MATEC Web of Conferences 40, 08001 (2016)

DOI: $10.1051 /$ matecconf/20164008001

(C) Owned by the authors, published by EDP Sciences, 2016

\title{
The Effect of the Rotor Static Eccentricity on the Electro-Mechanical Coupled Characteristics of the Motorized Spindle
}

\author{
Zaixin $\mathrm{Wu}^{1}$, Yajun Zhang ${ }^{1}$, Baomin Wang ${ }^{1}$, Xudong Tian ${ }^{1}$ \\ ${ }^{1}$ College of Electromechanical Engineering, Lanzhou University of Technology, Lanzhou, China
}

\begin{abstract}
High-speed motorized spindle is a multi-variable, non-linear and strong coupling system. The rotor static eccentricity is inevitable because of machining or assembling error. The rotor static eccentricities have an important effect on the electromechanical coupled characteristics of the motorized spindle. In this paper, the electromechanical coupled mathematical model of the motorized spindle was set up. The mathematical model includes mechanical and electrical equation. The mechanical and electrical equation is built up by the variational principle. Furthermore, the inductance parameters without the rotor static eccentricity and the inductance parameters with rotor static eccentricity have been calculated by the winding function method and the high speed motorized spindle was simulated. The result show that the rotor static eccentricity can delay the starting process of the motorized spindle, and at steady state, the rotor circuit currents are still large because of the rotor static eccentricity.
\end{abstract}

\section{Introduction}

The high speed motorized spindle is a multi-variable, non-linear and strong coupling system. The electromechanical coupled phenomenon of motorized spindle has an important influence to its performance. Currently, each components of the high-speed motorized spindle is designed individually. This method separate mechanical parameters from electromagnetic parameters and thermal parameters of spindle system. Consequently, the electro-mechanical coupled phenomenon of the highspeed motorized spindle is neglected. So it is necessarily to analyze the multi-physical processes and multidimensional coupling characteristics of the highspeed motorized spindle.

Generally, the multi-physical coupled phenomenon of the high-speed motorized spindle unit has attracted attention in the literature. The thermal model was coupled with the spindle dynamic model through bearing heat generation and thermal expansion of the whole system based on the bearing configuration. The thermomechanical model of the high-speed motorized spindle was set up in. It was shown that bearing orientation had a significant effect on spindle stiffness. A complete bearing load-deflection analysis including thermal expansion was derived and was coupled with an analysis of spindle dynamic response in. Several methods setting up the electro-mechanical coupling modeling were given in. Founded on the calculus of variations, the electromechanical coupling dynamical model of the motorized spindle was developed in, which provided the theoretical basis for further research on the electromechanical coupled dynamical performance of high speed motorized spindle system. A modified mechanical-electric coupling model of the high speed grinding motorized spindle was created in, and a new strategy of suppressing high-order harmonic mechanicalelectric coupling vibration by optimizing inverter operating parameters was proposed. An integrated model was presented in to study the electro-thermo-mechanical coupled dynamic characteristics of motorized spindles. And the coupling relationship among the electrical, thermal, and mechanical behaviors of the motorized spindle was explained. In order to predict and control the thermal properties of motorized spindles under work condition and their effects on the dynamic characteristics effectively, a bearing thermomechanical dynamic model which takes preload methods and thermal responses into account is presented in, and then friction loss and support stiffness of the bearing are analyzed.

The present studies have got great achievements on thermo-mechanical coupled and electro-mechanical coupled properties of the motorized spindle. However, the rotor static eccentricities also have an important effect on the electromechanical coupled characteristics of the motorized spindle. In this paper, the electromechanical coupled mathematical model of the motorized spindle was set up and the high speed motorized spindle was simulated. The effect of the rotor static eccentricity on the electromechanical coupled characteristics of the motorized spindle is revealed.

\section{The electromechanical coupled mathematical model of high speed motorized spindle}




\subsection{The Structure Characteristics of the Motorized Spindle}

The motor of the high-speed motorized spindle is directly attached inside the spindle housing and mounted on the rotating shaft by interference fit. The spindle of the machine tool is directly driven by the motor. Discarding the traditional belt drive and gear drive, the high-speed motorized spindle is a new structure of the spindle and it makes the high-speed machine tool achieve to zerotransmission. Eliminating the intermediate links between the electric motor and the spindle, which greatly simplifies the structure of the main transmission system of the machine tools and the power of the motor is passed to the tool of the machine tools directly. Figure1 is a typical structure of the high-speed motorized spindle.

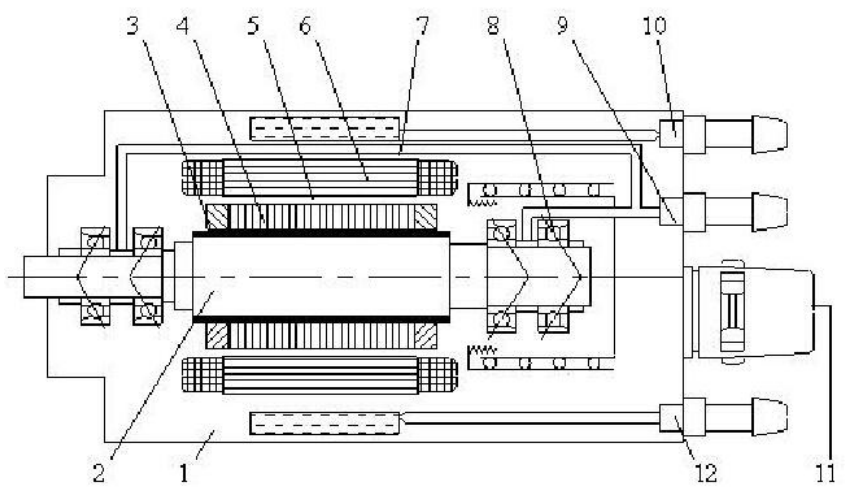

Figure 1. A typical structure of the high-speed motorized spindle

1. spindle housing 2. spindle 3. Interference connection sleeve 4.rotor 5. air gap 6.stator 7.coolant jacket

8.bearing 9. lubricating oil entrance 10. coolant outlet11. power interface 12. coolant entrance

\subsection{The Physical Model of the High-Speed Motorized Spindle}

The motor of the high-speed motorized spindle is directly mounted on the rotating shaft by interference fit. Figure 2 is its physical model.

Theoretically, the high-speed motorized spindle can be regarded as a high speed motor in. According to the structure characteristics of motorized spindle, the motorized spindle can be simplified as a high speed motor. When the three-phase alternating current inputted into the stator winding of the high speed electric spindle, the stator winding produces a rotating magnetic field. The rotating magnetic field passes through the air gap and chains with the rotor winding. Simultaneously, the rotating magnetic field cuts the rotor winding and the three-phase induction current emerges in the rotor winding. The rotor current is affected by the magnetic force in the magnetic field, which makes the rotor whirling.

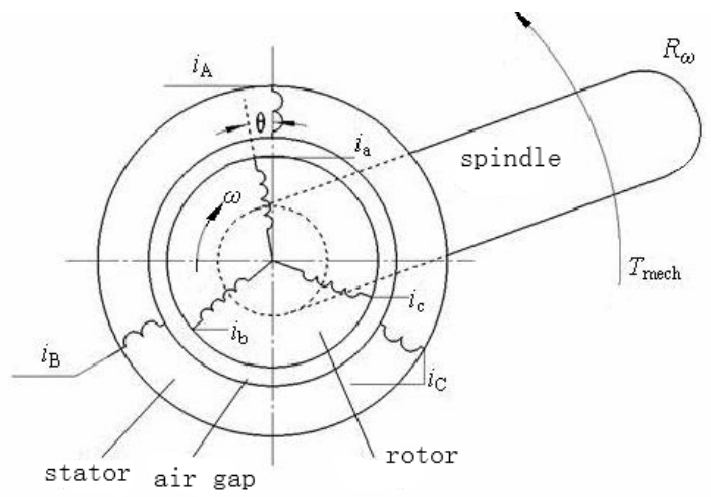

Figure 2. The physical model of the high-speed motorized spindle

\subsection{The Electromechanical Coupled Mathematical Model of High-Speed Motorized Spindle}

Grounded the physical model, using the variational principle the electromechanical coupled mathematical model of high speed motorized spindle can be set up $^{[9]}$.

The kinetic energy of the system is

$$
T=W_{m}+W_{\text {mech }}=\frac{1}{2} \sum_{j} \sum_{m} L_{j m} i_{j} i_{m}+\frac{1}{2} J \theta^{2}
$$

where ${ }^{j, m}$ stand for $A, B, C, a, b, c$ and $W_{m}$ is the kinetic energy of the electromagnetic system and $W_{\text {mech }}$ is the kinetic energy of mechanical system and ${ }^{L_{j m}}$ is the inductance parameters of electromagnetic system and ${ }^{J}$ is moment of inertia.

The potential energy of the system is

$$
V=0
$$

Lagrange function is

$$
L=T-V=T
$$

The dissipation function of the system is

$$
F_{R}=\frac{1}{2} R_{s} \sum_{k=1}^{3} i^{2}+\frac{1}{2} R_{r} \sum_{k=4}^{6} i^{2}+\frac{1}{2} R_{n} n^{2}
$$

where $R_{s}$ is the stator resistance and $R_{r}$ is the rotor resistance and $R_{n}$ is the electromagnetic loss impedance and ${ }^{n}$ is speed of the rotor.

The voltage of each loop is regarded as the generalized force. Substituting equation (1), (2), (3), (4) into the Lagrange equation, can get the voltage equation of each loop.

$$
\mathbf{U}=\mathbf{L} \frac{\mathrm{d} \mathbf{I}}{\mathrm{d} t}+\mathbf{I} \frac{\mathrm{d} \mathbf{L}}{\mathrm{d} t}+\mathbf{I} \mathbf{R}
$$

As usual $\mathbf{U}$ is the voltage matrix, $\mathbf{L}$ is the matrix of inductance, $\mathbf{I}$ is the current matrix, $\mathbf{R}$ is the resistance matrix. The external load $W_{\text {mech }}$ is regarded as the 
generalized force. The mechanical equation of the system is

$$
T_{e}=J \frac{d n}{d t}+R_{n} n+T_{\text {mech }}
$$

The electromechanical coupled mathematical model of high speed motorized spindle includes the voltage equation of each loop and the mechanical equation of the system. Simultaneous equations of voltage equation and mechanical movement equation are the mathematical model of the system. Therefore, the electro-mechanical coupled mathematical model of the high speed motorized spindle is

$$
\left\{\begin{array}{l}
\mathbf{U}=\mathbf{L} \frac{\mathrm{d} \mathbf{I}}{\mathrm{d} t}+\mathbf{I} \frac{\mathrm{d} \mathbf{L}}{\mathrm{d} t}+\mathbf{I R} \\
T_{e}=J \frac{\mathrm{d} n}{\mathrm{~d} t}+R_{n} n+T_{m e c h} \\
\frac{\mathrm{d} \theta}{\mathrm{d} t}=n_{p} n
\end{array}\right.
$$

where ${ }^{n_{p}}$ is pole number of the motor and

$$
T_{e}=\frac{1}{2} n_{P} \mathbf{I}^{\mathrm{T}} \mathbf{L} \mathbf{I}
$$

In order to further study on the spindle system, the unknown parameters in the mathematical model must be calculated. The most important parameters are the inductance parameters of each loop. Because of machining or assembling error, the rotor static eccentricity is inevitable. The static eccentricity of the rotor leads to emerge the dislocation between the stator and the rotor. The dislocation can cause distortion of the inductance parameters. So, the inductance parameters of each loop with static eccentricity must be calculated.

\section{The inductance parameters calculation}

\subsection{The effective air-gap length}

If the rotor exists static eccenticity, the air-gap length must be fixed. The effective air-gap length in the case of eccentricity can be described as, ${ }^{[10]}$

$$
a(\theta)=a_{0}-a_{0} \rho \cos \theta
$$

where $\theta$ is the angular position of winding and $a_{0}$ is the air-gap length in the case of no eccentricity and $\rho$ is degree of eccentricity.

\subsection{The Winding Function}

The winding function is the function of air gap magnetic wave inputting one ampere of current into the winding. As show in ${ }^{[11]}$, the winding function of winding $\mathrm{x}$ is given by

$$
P(\theta)=\frac{2}{a_{0} \sqrt{1-a^{2}(\theta)}} \sum_{i=0}^{\infty}\left(\frac{1-\sqrt{1-a^{2}(\theta)}}{a(\theta)}\right) \cos i \theta
$$

where $i$ is the ordinal number of the current harmonics.

\subsection{The Expression for Inductance Parameters}

The inductance between any two windings " $x$ " and " $y$ " in any electrical machine is given by the following expression, ${ }^{[12]}$

$$
L_{x y}=\mu_{0} l r \int_{-\pi}^{\pi} P_{\mathrm{x}}(\theta) P_{\mathrm{y}}(\theta) a^{-1}(\theta) \mathrm{d} \theta
$$

where $P_{\mathrm{x}}(\theta)$ is winding function of the winding “ $x$ " and $P_{y}(\theta)$ is winding function of the winding " $y$ " and $\mu_{0}$ is permeability of vacuum and $l$ is the length of the stack, $r$ is the radius of the stator.

The element of the matrix of inductances in expression (7) and (8) can be calculated by the expression (11). So all inductance parameters can be calculated. The basic parameters of the specific high speed motorized spindle studied in this paper are show in Table I .

Table I Original parameters of the high speed motorized spindle

\begin{tabular}{cc|cc|cc}
\hline Parameter & Parameter value & Parameter & Parameter value & Parameter & Parameter value \\
\hline $\begin{array}{c}\text { Rated power } \\
(\mathrm{kw})\end{array}$ & 20 & $\begin{array}{c}\text { Rated current } \\
(\mathrm{A})\end{array}$ & 46 & $\begin{array}{c}\text { Rotor resistance } \\
(\Omega)\end{array}$ & 2.00 \\
$\begin{array}{c}\text { Rated speed } \\
(\mathrm{kr} / \mathrm{min})\end{array}$ & 15 & $\begin{array}{c}\text { Rated torque } \\
(\mathrm{Nm})\end{array}$ & 12.7 & Pole number \\
$\begin{array}{c}\text { Rated voltage } \\
(\mathrm{V})\end{array}$ & 350 & $\begin{array}{c}\text { Stator resistance } \\
(\Omega)\end{array}$ & 0.50 & Rotor slot & 28 \\
\hline
\end{tabular}

The inductance parameters matrix of the stator

\subsection{Inductance Parameters of the Stator} without the rotor static eccentricity is

According the relative position of each stator coil, the inductance parameters of the stator can be calculated by expression (10). 
$\mathbf{L}_{s s}=\left[\begin{array}{ccc}0.2614 & -0.1362 & -0.1362 \\ -0.1362 & 0.2614 & -0.1362 \\ -0.1362 & -0.1362 & 0.2614\end{array}\right]$

The inductance parameters matrix of the stator with $20 \%$ rotor static eccentricity is

$\mathbf{L}_{s s}=\left[\begin{array}{ccc}0.2645 & -0.1358 & -0.1358 \\ -0.1189 & 0.2645 & -0.1358 \\ -0.1358 & -0.1358 & 0.2645\end{array}\right]$

\subsection{Inductance Parameters of the Rotor}

The inductance parameters matrix of the rotor $\mathbf{L}_{r r}$ is $29 \times 29$. Figure 3 shows the inductance parameter between $1^{s t}$ rotor loop and other rotor loop without the rotor static eccentricity. In Figure $7 \mathrm{n}$ is the serial number of the rotor loop. Figure4 shows the inductance parameter between $1^{s t}$ rotor loop and other rotor loop with $20 \%$ rotor static eccentricity.

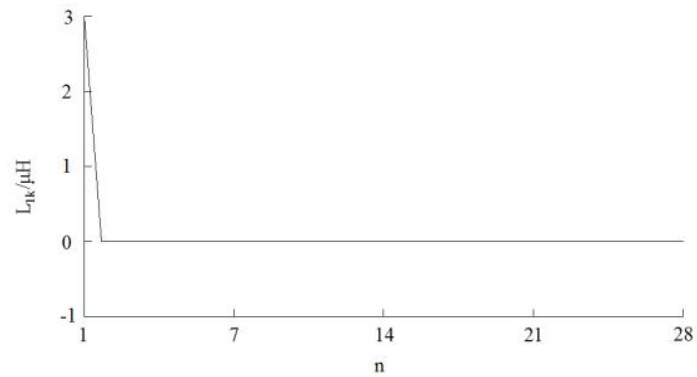

Figure 3. The inductance between rotor loop and other rotor loop without the rotor static eccentricity

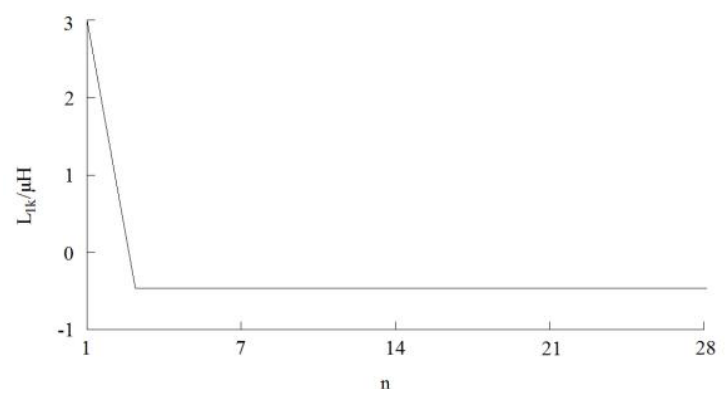

Figure 4. The inductance between rotor loop and other rotor loop with $20 \%$ rotor static eccentricity.

\subsection{Inductance Parameters between the Stator and the Rotor}

Figure5 shows the inductance parameter between the phase A of the stator and each of rotor loops without the rotor static eccentricity. Figure6 shows the inductance parameter between phase A of the stator and each of rotor loops with $20 \%$ rotor static eccentricity.

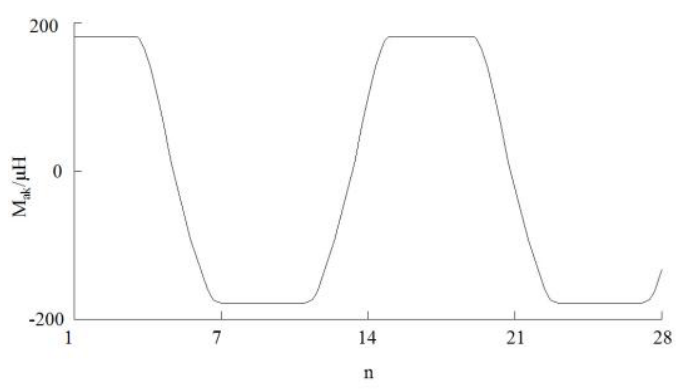

Figure 5. The inductance between the phase A of the stator and each of rotor loop without the rotor static eccentricity

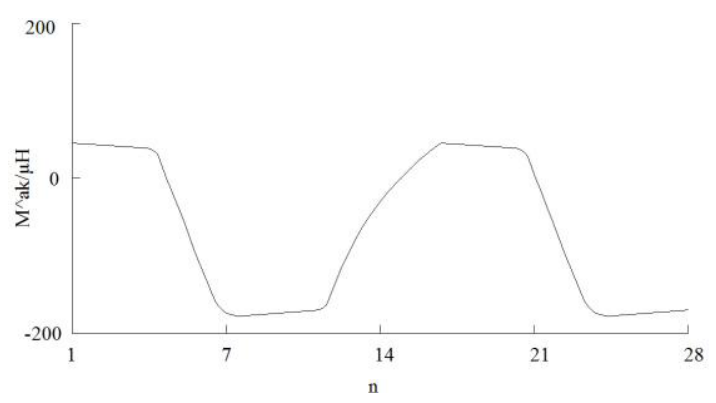

Figure 6. The inductance between phase $\mathrm{A}$ of the stator and each of rotor loop with $20 \%$ rotor static eccentricity

\section{Simulations and verification}

According to the expression (7), the state equation of the high speed motorized spindle can be summed as

$$
\frac{\mathrm{d}}{\mathrm{d} t}\left[\begin{array}{l}
\mathbf{I} \\
n \\
\theta
\end{array}\right]=\left[\begin{array}{ccc}
-\mathbf{L}\left(\frac{\mathrm{d} \mathbf{L}}{\mathrm{d} t}+\mathbf{R}\right) & 0 & 0 \\
\frac{1}{2 \mathrm{~J}} \mathbf{I}^{\mathrm{T}} \frac{\partial \mathbf{L}}{\partial \theta} & 0 & 0 \\
0 & 1 & 0
\end{array}\right]\left[\begin{array}{l}
\mathbf{I} \\
n \\
\theta
\end{array}\right]+\left[\begin{array}{cc}
\mathbf{L}^{-1} & 0 \\
0 & -\frac{1}{\mathbf{J}} \\
0 & 0
\end{array}\right]\left[\begin{array}{c}
u \\
\mathrm{~T}_{\text {mech }}
\end{array}\right]
$$

Using the basic parameters in Table. 1 and the inductance parameters calculated previously, the high speed motorized spindle was simulated. The motorized spindle is started without load and the load of $10 \mathrm{Nm}$ is applied to the motorized spindle after completing the starting process (When the motorized spindle operates for 20s, the load of $10 \mathrm{Nm}$ is applied to the motorized spindle).

Figure7 shows the stator phase " $A$ " current, rotor current, spindle speed and electromagnetic torque for noload condition without the rotor static eccentricity. Figure8 shows the stator phase " $\mathrm{A}$ " current, rotor current, spindle speed and electromagnetic torque for no-load condition with $20 \%$ rotor static eccentricity.

As show in Figure7, it took 10s to complete the starting process and the rotor circuit current is very low 
after the motorized spindle entering the rated condition without load. After the load of $10 \mathrm{Nm}$ is applied to the motorized spindle, the motorized spindle quickly enter a new dynamic equilibrium. As show in Figure8, it took $15 \mathrm{~s}$ to complete the starting process and the rotor circuit current is still large after the motorized spindle entering the rated condition without load. After the load of $10 \mathrm{Nm}$ is applied to the motorized spindle, the motorized spindle enter a new dynamic equilibrium slowly.
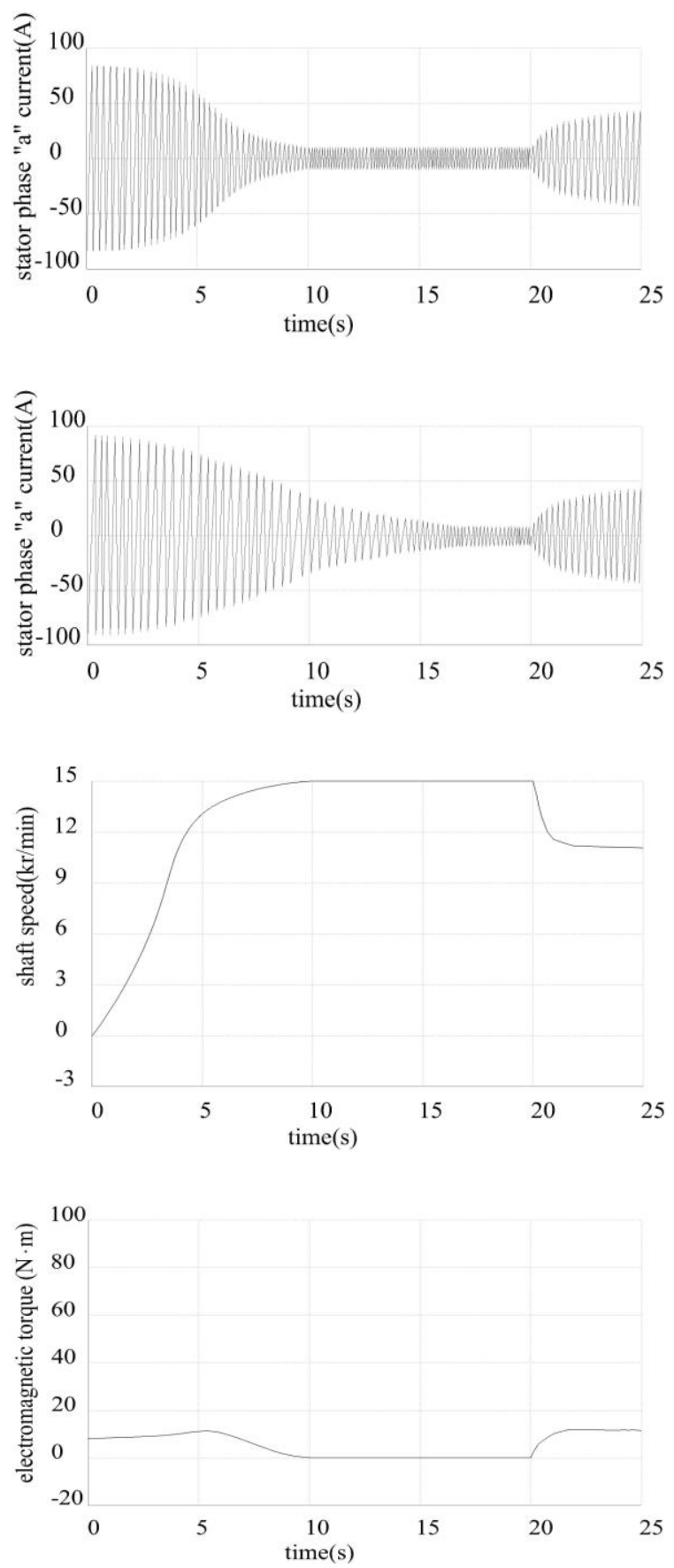

Figure7. The stator phase "A" current, rotor current, spindle speed and electromagnetic torque without the rotor static eccentricity
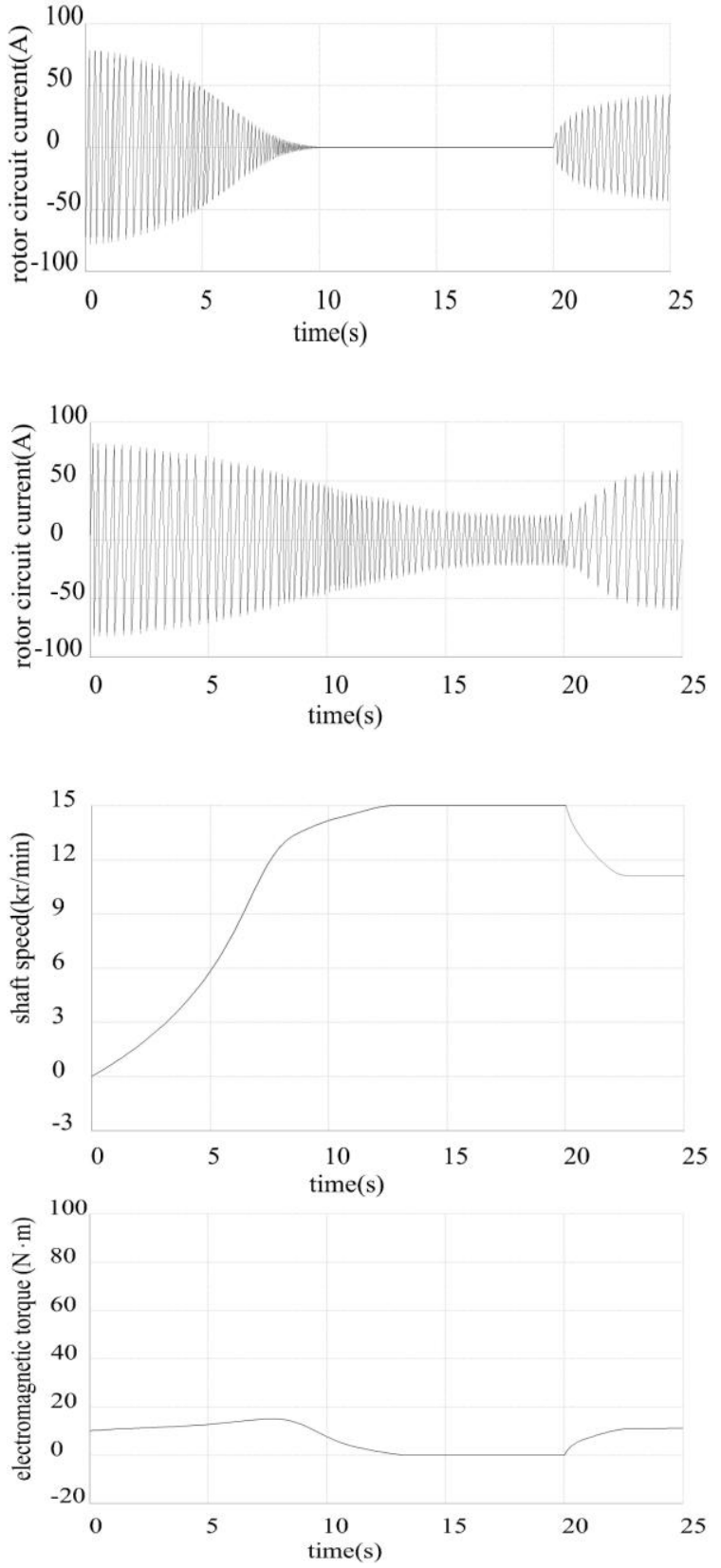

Figure 8. The stator phase "A" current, rotor current, spindle speed and electromagnetic torque with $20 \%$ rotor static eccentricity

Compared Figure7 with Figure8, it is clear that the starting time under $20 \%$ rotor static eccentricity is larger than under healthy rotor. Because of the rotor static eccentricity, the magnetomotive force in air gap is delayed. The process magnetic energy transforming into mechanical energy is delayed, so the start time is extended.

It is clear that at steady state, the rotor circuit currents in healthy motorized spindle are very low and can be neglected. However, the rotor circuit currents under $20 \%$ rotor static eccentricities are also large. At steady state, the spindle speed very close to the synchronous speed. The cutting action between the rotor and rotating magnetic field is very weak so the rotor circuit currents in healthy motorized spindle are very low. Under $20 \%$ rotor static eccentricity, although the rotor speed is very close 
to synchronous speed, the cutting action between the rotor and rotating magnetic field is also strong because of the rotor static eccentricity. The induced electromotive force in the rotor is still high so the rotor circuit currents under $20 \%$ rotor static eccentricities are also large.

In addition, after the load is applied to the motorized spindle, it takes more time to enter a new dynamic equilibrium in Figure8. This delay in achieving the new dynamic equilibrium can attribute to the generation of backward magnetomotive force due to the static eccentricity.

\section{Conclusions}

This paper has set the electromechanical coupled mathematical model of high speed motorized spindle by variational principle. The mathematical model can quantificational explain the mechanical-electrical energy conversion, particularly the mutuality between inputting voltage, electric current, outputting torque and rotate speed. The inductance parameters without the rotor static eccentricity and the inductance parameters with $20 \%$ rotor static eccentricity have been calculated. Furthermore, the high-speed motorized spindle was simulated and the following have been proved conclusively.

1) The rotor static eccentricity can delay the starting process of the high speed motorized spindle.

2) At steady state, the rotor circuit currents are still large because of the rotor static eccentricity.

3) After the load is applied to the motorized spindle, it takes more time to enter a new dynamic equilibrium because of the rotor static eccentricity.

\section{Acknowledgement}

This work is financially supported by the National Naturel Science Foundation of China (No. 51165024) and Naturel Science Foundation of Gansu Province (No. 1208RJZA131) .

\section{References}

1. Li H, Shin $\mathrm{Y}$ C. Analysis of bearing configuration effects on high speed spindles using an integrated dynamic thermo-mechanical spindle model [J]. International Journal of Machine Tools and Manufacture, 2004, 44(4): 347-364.

2. Jorgensen B R, Shin Y C. Dynamics of machine tool spindle/bearing systems under thermal growth [J]. Journal of Tribology, 1997, 119(4): 875-882.

3. C.Brecher, SpachtholzG, PaepenmullerF. Developments for high Performance machine tool spindles[J]. CIRP Annals-Manufacturing Technology, 2007, 56(1): 395 399.
4. [4]Meng Jie, Chen Xiaoan, He Ye. Electromechanical coupled dynamical modeling of high speed motorized spindle's motor-spindle subsystem $[\mathrm{J}]$. Chinese Journal Of Mechanical Engineering, 2007, 43(12): 160 165.

5. Kang Huimin, Li Huiqiang, Meng jie, Liu Deshun, Deng Zhaohui,Zhou Zhijin,Hu Binling. Research on the high-speed motorized spindle electro-mechanical coupling modeling and simulation $[\mathrm{J}]$. Journal of Hunan University of Science \& Technology, 2012, 27(4): 18 22.

6. Lu L, Xiong W, Gao H. Mechanical-electric coupling dynamical characteristics of an ultrahigh speed grinding motorized spindle system[J]. Chinese Journal of Mechanical Engineering, 2008, 21(5): 34-40.

7. Liu J, Chen X. Dynamic design for motorized spindles based on an integrated model $[\mathrm{J}]$. The International Journal of Advanced Manufacturing Technology, 2014, 71(9-12): 1961-1974.

8. Chen Xiaoan, Liu Junfeng, He Ye, Zhang Peng, Shan Wentao. Thermal Properties of High Speed Motorized Spindle and Their Effects [J]. Journal of Mechanical Engineering, 2013,49(11):135142.

9. Li X, Wu Q, Nandi S. Performance analysis of a three-phase induction machine with inclined static eccentricity[J]. Industry Applications, IEEE Transactions on, 2007, 43(2): 531-541.

10. Kang Huimin, Li Huiqiang, Meng jie, Liu Deshun, Deng Zhaohui,Zhou Zhijin,Hu Binling. Research on the high-speed motorized spindle electro-mechanical coupling modeling and simulation [J]. Journal of Hunan University of Science \& Technology, 2012, 27(4): 18 22.

11. Faiz J, Tabatabaei I. Extension of winding function theory for nonuniform air gap in electric machinery[J]. Magnetics, IEEE Transactions on, 2002, 38(6): 3654-3657.

12. Luo X, Liao $\mathrm{Y}$, Toliyat $\mathrm{H}$ A, et al. Multiple coupled circuit modeling of induction machines[J]. Industry Applications, IEEE Transactions on, 1995, 31(2): 311-318. 